\title{
Avaliação da influência de diferentes tratamentos térmicos sobre as transformações de fases esmectitas
}

\author{
(Evaluation of the effect of different heat treatments on the \\ ssmectite phases transformation)
}

\author{
W. P. Gonçalves, V. J. Silva, J. Gomes, R. R. Menezes, G. A. Neves, H. C. Ferreira, L. N. L. Santana \\ ${ }^{1}$ Unidade Acadêmica de Engenharia dos Materiais, Universidade Federal de Campina Grande, Av. Aprígio \\ Veloso 882, Campina Grande, PB, Brasil 58109-970 \\ wherllyson@yahoo.com.br,lisiane@dema.ufcg.edu.br, gelmires@dema.ufcg.edu.br,heber@dema.ufcg.edu.br
}

\begin{abstract}
Resumo
Argilas esmectitícas têm sido usadas em diversas aplicações tecnológicas, principalmente em massas cerâmicas tradicionais, por garantirem a plasticidade necessária para a conformação a verde e, simultaneamente, promoverem o desenvolvimento de cristais de mulita durante a queima, fase que confere resistência mecânica ao produto final. Uma inovação importante nas últimas décadas no setor cerâmico é a utilização de queima rápida, o que pode induzir mudanças durante as transformações térmicas das matérias-primas e de suas misturas. Para se implementar mudanças nos parâmetros de queima é de fundamental importância o conhecimento prévio das transformações de fases das argilas e das massas, sendo necessária em algumas situações a formulação de novas composições. O objetivo deste trabalho é analisar a influência de diferentes tratamentos térmicos sobre as mudanças mineralógicas e microestruturais de esmectitas, enfatizando a presença da fase mulita. Foram utilizadas três argilas, duas nacionais e uma importada. As amostras foram inicialmente submetidas a um processo de beneficiamento. Posteriormente, foram submetidas às caracterizações química e mineralógica por meio das seguintes técnicas: análise química por fluorescência de raios $\mathrm{X}$, análise termogravimétrica e análise térmica diferencial, em seguida a um tratamento térmico na faixa de temperaturas entre 800 e $1250{ }^{\circ} \mathrm{C}$, com taxa de aquecimento 30 ${ }^{\circ} \mathrm{C} / \mathrm{min}$ e tempo de permanência de $10 \mathrm{~min}$. Os resultados evidenciaram que é possível obter mulita a partir de argilas esmectíticas, e que a composição da argila e a temperatura influenciaram sobre a quantidade de mulita formada.
\end{abstract}

Palavras-chave: esmectita, tratamento térmico, transformações de fases, mulita.

Abstract

Smectite clays have been used in various technical applications, particularly in traditional ceramic material, for ensuring the plasticity required for the forming green and simultaneously promote the development of mullite crystals during the firing phase, which confers mechanical strength to the final product. An important innovation over the past decades in the ceramic sector is the use of fast firing, which can induce changes during thermal processing of raw materials and mixtures. To implement changes in firing parameters it is crucial the knowledge of phase transformations of clays, being necessary in some situations the formulation of new compositions. The aim of this work is to analyze the influence of different heat treatments on the mineralogical and microstructural changes of smectites, emphasizing the presence of mullite. Two samples of natural bentonite and one imported commercial were used. The natural samples were initially subjected to a milling process. Subsequently, they were submitted to chemical analysis by X-ray fluorescence, thermogravimetric and differential thermal analyses. The clays were treated in the $800-1250{ }^{\circ} \mathrm{C}$ range with a heating rate $30{ }^{\circ} \mathrm{C} / \mathrm{min}$ and kept at the maximum temperature for $10 \mathrm{~min}$. The results showed that the clay composition and the temperature have influence on the amount of mullite formed.

Keywords: smectite, heat treatment, phase transformations, mullite.

\section{INTRODUÇÃO}

Argilas são as matérias-primas básicas utilizadas nas indústrias de produtos da cerâmica tradicional, como em telhas, blocos, e produtos da cerâmica branca (louça sanitária, louça de mesa e isolantes elétricos) [1]. No entanto, nas últimas décadas estão sendo cada vez mais utilizadas em aplicações mais avançadas, por exemplo, em suportes de catalisadores, como aditivos para cimentos e na indústria de refratários. Durante o aquecimento de argilas diferentes reações termoquímicas ocorrem e a sequência de transição de fase e a composição das fases dependem do tipo e da composição das argilas, assim como, do tratamento térmico [2]. Quando essas são submetidas à temperaturas acima de $1000{ }^{\circ} \mathrm{C}$, normalmente, a microestrutura final contém diferentes formas de cristais de mulita e grãos de quartzo não dissolvidos dispersos na matriz vítrea. $\mathrm{Na}$ microestrutura final, os cristais de mulita apresentam várias formas, composição e tamanhos e são controlados pela fluidez da fase líquida da qual eles precipitaram. A formação desta fase depende das interações entre os diversos óxidos presentes na composição e pode ser afetada por qualquer 
variação no tratamento térmico. O tamanho e a forma dos cristais estão associados à fluidez da matriz líquida das quais estes precipitaram, a temperatura e a composição.

As reações de mulitização a partir de argilas geralmente produzem sílica amorfa, esta pode reagir com íons de alumina dispersos para formar mulita secundária ou recristalizar para $\mathrm{SiO}_{2}$. Esta competição pode resultar em uma microestrutura que nem sempre é favorável a resistência mecânica das peças cerâmicas [3]. O aumento do tamanho de grão e da quantidade de fase vítrea pode comprometer as propriedades mecânicas dos materiais cerâmicos [4].

Alguns pesquisadores [5] já analisaram o efeito das impurezas no sistema $\mathrm{Al}_{2} \mathrm{O}_{3}$ e $\mathrm{SiO}_{2}$. Estes mostraram que, de um modo geral, a presença de impurezas reduz a temperatura de formação do líquido rico em sílica e diminui a viscosidade, favorecendo o processo de nucleação da mulita. As impurezas, quando em solução na estrutura cristalina da mulita, abaixam a energia de superfície em algumas direções do cristal, levando a um crescimento preferencial nas outras direções, resultando na formação de grãos alongados. Portanto, quanto maior a solubilidade da impureza na mulita, mais acicular será o formato do cristal. Os cristais de mulita obtidos a partir de aluminossilicatos apresentam morfologia acicular, em formato de agulhas, para composições ricas em sílica, enquanto nas composições ricas em alumina tendem a ser mais equiaxiais [6].

As fases formadas na queima de argilas do grupo da ilita e da esmectita têm sido estudadas por muitos anos, mas existem relativamente poucos estudos abordando a evolução da microestrutura destes materiais [8]. Alguns trabalhos [7-10] foram realizados buscando-se obter informações referentes às transformações térmicas que ocorrem quando as bentonitas são submetidas a aquecimento em elevadas temperaturas.

Segundo Mcconville e Lee [11], que analisaram as transformações de fases de argilas esmectitas submetidas a tratamento térmico entre 800 e $1300{ }^{\circ} \mathrm{C}$, os picos característicos do argilomineral ainda foram detectados até $800{ }^{\circ} \mathrm{C}$; no entanto, a $900{ }^{\circ} \mathrm{C}$ não foram observados picos característicos. Os picos da fase espinélio começam a ser detectados a partir de $900{ }^{\circ} \mathrm{C}$ até $1200{ }^{\circ} \mathrm{C}$, e a cristobalita cristaliza acima de $1000{ }^{\circ} \mathrm{C}$. A cristalização da mulita começa em $1100{ }^{\circ} \mathrm{C}$ e a intensidade dos picos aumentam com a temperatura. Com o aumento da temperatura (1200$1350^{\circ} \mathrm{C}$ ) a fase espinélio desaparece, surgem novas fases, a cordierita, cristobalita e mulita, no entanto, ainda observase a presença da fase vítrea rica em sílica (Fig. 1).

Foi observado que a $900{ }^{\circ} \mathrm{C}$ os picos característicos da montmorilonita desaparecem, e a $1000^{\circ} \mathrm{C}$ foram identificados picos de cordierita e quartzo [9]. A $1200{ }^{\circ} \mathrm{C}$ pode-se observar picos característicos da cristobalita, cordierita e mulita. Quando o tratamento térmico atingiu $1350{ }^{\circ} \mathrm{C}$, os picos de mulita e cristobalita apresentaram menor intensidade, sendo observada uma maior quantidade da cordierita rica em $\mathrm{Fe}$. O processo de formação da mulita a partir de argilas muitas vezes apresenta algumas dificuldades devido à presença de impurezas nas argilas naturais [8]. No entanto,

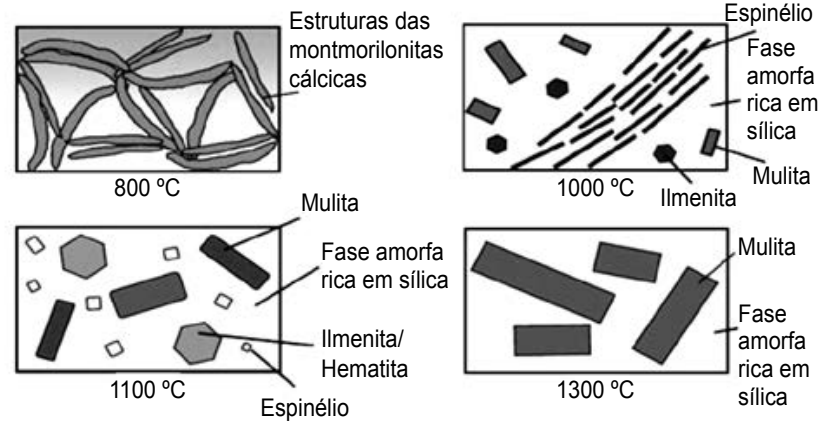

Figura 1: Transformações térmicas observadas em uma argila montmorilonitica [11].

[Figure 1: Summary of thermal transformations observed in a montmorillonite clay [11].]

há uma compreensão básica da decomposição da argila e a seqüência de fases de cristalização de acordo com o material de partida e tipo de processamento. Diante deste contexto, neste trabalho foram analisadas as mudanças mineralógicas e microestruturais de esmectitas contendo caulinita, quando submetidas a diferentes tratamentos térmicos, enfatizando a presença da fase mulita.

\section{MATERIAIS E MÉTODOS}

Para o desenvolvimento deste trabalho foram utilizadas três amostras de argilas esmectíticas, sendo duas naturais e uma industrializada. As argilas esmectíticas naturais foram denominadas Branca (A) e Cinza (B), provenientes do município de Cubatí, PB. A terceira amostra, closite $\mathrm{Na}^{+}$, proveniente da empresa "Southern Clay", Gonzáles, TX, Estados Unidos, foi denominada amostra C. As amostras A e B foram secas em estufa a $60{ }^{\circ} \mathrm{C}$, posteriormente moídas em moinho de galga por $4 \mathrm{~h}$ e submetidas a peneiramento em peneira vibratória ABNT $200(0,074$ $\mathrm{mm})$. A amostra $C$, por ser industrializada, não passou pelo processo de beneficiamento. Em seguida as amostras foram caracterizadas química, térmica e mineralogicamente.

A caracterização foi efetuada por meio das seguintes técnicas: análise química por fluorescência de raios X (EDX 720 Shimadzu), análise termogravimétrica (TG) e análise térmica diferencial (ATD), temperatura máxima de 1000 ${ }^{\circ} \mathrm{C}$, com taxa de aquecimento $12,5{ }^{\circ} \mathrm{C} / \mathrm{min}$ sob atmosfera de ar (equipamento RB-300, BP Eng.), difração de raios X (D6000 Shimadzu) com radiação Cuka $(40 \mathrm{kV} / 30 \mathrm{~mA}) \mathrm{e}$ rotação do goniômetro de $2 \%$ min e passo $0,02^{\circ}$, com faixa de $5^{\circ}$ a $60^{\circ}$.

Após a etapa de caracterização, as argilas foram submetidas a tratamentos térmicos a 800, 900, 1000, 1100, 1200 e $1250{ }^{\circ} \mathrm{C}$ com taxa de aquecimento $30{ }^{\circ} \mathrm{C} / \mathrm{min}$ com patamar de $10 \mathrm{~min}$.

Para analisar as transformações de fases ocorridas nos diferentes tratamentos térmicos, foi utilizada a técnica de difração de raios $\mathrm{X}$, aplicando-se os mesmos parâmetros citados acima para a identificação das fases na argila. Para a identificação e quantificação das fases cristalinas, foram utilizados os arquivos do banco de dados PCPDFWIN. 


\section{RESULTADOS E DISCUSSÃO}

A Tabela I apresenta a composição química das amostras A, B e C.

As amostras apresentaram perda de massa 8,83 a $13,92 \%$, que está relacionada à perda de água adsorvida e das hidroxilas dos argilominerais, assim como, a queima de matéria orgânica. Observou-se que o teor de $\mathrm{SiO}_{2}$ variou de 49,99 a 57,86\%, estando entre os encontrados para as bentonitas brasileiras e americanas [10]. Com relação ao teor de $\mathrm{Al}_{2} \mathrm{O}_{3}$, a amostra A apresentou maior porcentagem, favorecendo a relação alumina/sílica, que foi de 0,54 para esta amostra, para a amostra B 0,47 , e de 0,38 para a amostra C. Este é um parâmetro significativo para o processo de obtenção da mulita. As amostras A e B não apresentaram $\mathrm{Na}_{2} \mathrm{O}$, enquanto que a amostra $\mathrm{C}$ apresentou $2,50 \%$ deste óxido, o que está relacionado à sua formação geológica. Pode-se observar também que a amostra $B$ apresentou maior teor de $\mathrm{MgO}$, e a amostra A maior teor de $\mathrm{K}_{2} \mathrm{O}$, sendo estes óxidos, também, significativos para o processo de síntese da mulita, pois irão favorecer o processo de difusão devido à formação da fase líquida. Quanto ao $\mathrm{Fe}_{2} \mathrm{O}_{3}$, este variou de 3,82 a $4,66 \%$.

A Fig. 2 mostra os difratogramas de raios $\mathrm{X}$ das argilas esmectitícas A, B e C .

Analisando os difratogramas da Fig. 2, verificaram-se as seguintes fases mineralógicas: esmectita com distância interplanar basal de 15,35 e 4,43 ̊ para a amostra A; para a amostra B 15,35, 4,45 e 3,22 Å e, para a amostra C, 12,21, 4,45 e $3,11 \AA$. A presença do quartzo foi identificada nas amostras A, B e C com distâncias interplanares basais de $4,22,3,33,2,48$ e 1,66 Å para a amostra A. Para amostra B, distâncias interplanares basais de 4,22, 3,33, 2,48, 1,66 ̊. Para amostra C, 4,27, 3,34 e 1,69 A. Os picos característicos da esmectita foram identificados por meio do arquivo JCPDS 10-0357. Para confirmar a presença da esmectita, essas argilas foram analisadas com etileno glicol. Picos característicos de caulinita nas amostras A e B, também foram encontrados (JCPDS 14-0081) com distâncias interplanares basais de 7,10 e 7,17 $\AA$, enquanto na amostra $C$ não foi encontrada. Pode-se verificar que o $\mathrm{Fe}_{2} \mathrm{O}_{3}$ nas amostras $\mathrm{A}$, $\mathrm{B}$ e C (Tabela I) está provavelmente relacionado ao ferro presente na estrutura cristalina do argilomineral do grupo da esmectita, já que não foi observada a presença de goetita, hematita, ilita ou outras fases que poderiam ser fontes de óxidos e hidróxidos de ferro.
A Fig. 3 apresenta as curvas das análises térmica diferencial e gravimétrica das argilas. $\mathrm{Na}$ curva de ATD da amostra A (Fig. 3a) observaram-se as seguintes transformações térmicas: um grande pico endotérmico com temperatura máxima em $143,9^{\circ} \mathrm{C}$, característico da presença de água livre e da água adsorvida na superfície das partículas. A profundidade e a área deste pico são proporcionais à capacidade de adsorção de água da montmorilonita, servindo, também, como parâmetro para classificar se a mesma é cálcica ou sódica, quanto maior o conteúdo de água da esmectita mais largo e profundo será este pico [9]. Outro pico endotérmico na faixa de temperaturas entre 530 a $650{ }^{\circ} \mathrm{C}$ foi observado, relacionado à desidroxilação das argilas. A temperatura na qual a água estrutural começa a ser eliminada reflete a estabilidade da esmectita e é uma das formas de avaliar a resistência térmica [9]. Pode-se observar um pico exotérmico na faixa 910 a $980{ }^{\circ} \mathrm{C}$, característico da cristalização da fase espinélio. Com relação à análise gravimétrica (Fig. 3b), observou-se que ocorreu entre as temperaturas de 25 e $225{ }^{\circ} \mathrm{C}$ uma perda de massa de $12 \%$, característica da perda de água livre e adsorvida, e de $9 \%$ referente à perda de hidroxila entre 405 e $685{ }^{\circ} \mathrm{C}$, observando-se, portanto, uma perda total em torno de $21 \%$.

A amostra B (Fig. 3a) apresentou comportamento semelhante à amostra A. Podem-se observar as seguintes inflexões: o primeiro pico endotérmico com máximo a $151,91{ }^{\circ} \mathrm{C}$ é atribuído a presença de água livre e adsorvida; o pequeno pico endotérmico a $234,26{ }^{\circ} \mathrm{C}$ correspondente à presença de água coordenada aos cátions; o pico endotérmico com máximo em $582,25{ }^{\circ} \mathrm{C}$, característico da perda de hidroxilas; um pico exotérmico a $935,23{ }^{\circ} \mathrm{C}$ típico do surgimento da fase espinélio. Com relação à análise gravimétrica (Fig. 3b) observou-se que ocorreu entre 25 e $315{ }^{\circ} \mathrm{C}$ uma perda de massa de $14 \%$ característica da perda de água livre e água adsorvida, e de $9 \%$ entre 405 e $675{ }^{\circ} \mathrm{C}$ referente à desidroxilação dos argilominerais. A perda de massa total foi de $23 \%$. Analisando a curva de ATD da amostra C (Fig. 3a) foram observadas as seguintes transformações térmicas: grande pico endotérmico com máximo em $160,76^{\circ} \mathrm{C}$, característico da presença de água livre e adsorvida; pico intenso endotérmico com no máximo $711,86^{\circ} \mathrm{C}$, característico da desidroxilação do argilomineral, um pico endotérmico a $874,35^{\circ} \mathrm{C}$ característico da destruição da estrutura da esmectita, e um pico exotérmico com máximo em $914,53{ }^{\circ} \mathrm{C}$, característico da fase espinélio. Com relação à análise gravimétrica (Fig. 3b), observou-se que

Tabela I - Composição química das argilas esmectitícas A, B e C.

[Table I - Chemical composition of smectite clays A, B and C.]

\begin{tabular}{ccccccccccc}
\hline \multirow{2}{*}{ Amostras } & \multicolumn{1}{c}{$\mathrm{SiO}_{2}$} & $\mathrm{Al}_{2} \mathrm{O}_{3}$ & $\mathrm{Fe}_{2} \mathrm{O}_{3}$ & $\mathrm{MgO}$ & $\mathrm{Na}_{2} \mathrm{O}$ & $\mathrm{K}_{2} \mathrm{O}$ & $\mathrm{CaO}$ & $\mathrm{TiO}_{2}$ & Outros Óxidos & PF \\
\hline $\mathrm{A}$ & 49,99 & 27,49 & 4,16 & 1,98 & 0,00 & 0,85 & 0,56 & 0,98 & 0,44 & 13,50 \\
$\mathrm{~B}$ & 51,74 & 24,76 & 3,82 & 3,10 & 0,00 & 0,72 & 0,67 & 0,83 & 0,40 & 13,92 \\
$\mathrm{C}$ & 57,86 & 22,42 & 4,66 & 2,23 & 2,50 & 0,05 & 0,72 & 0,00 & 0,69 & 8,83 \\
\hline
\end{tabular}

PF - Perda ao fogo determinada com a queima a $1000^{\circ} \mathrm{C}$, após secagem a $110^{\circ} \mathrm{C}$. 

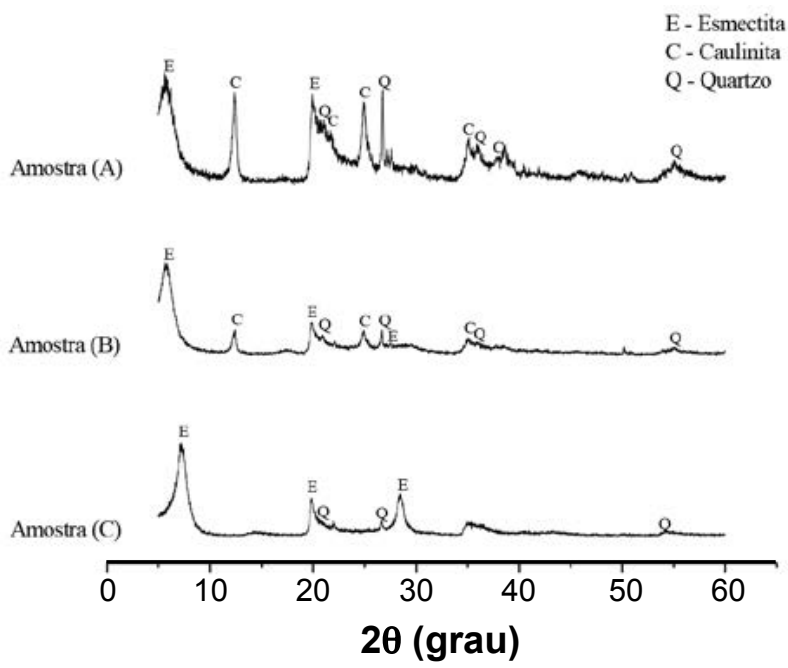

Figura 2: Difratogramas de raios $\mathrm{X}$ das amostras A, B e C. [Figure 2: XRD patterns of the samples $A, B$ and $C$.]

ocorreu entre $25{ }^{\circ} \mathrm{C}$ e $280{ }^{\circ} \mathrm{C}$ uma perda de massa de $11 \%$, característica da perda de água livre e água adsorvida, entre 580 e $815^{\circ} \mathrm{C}$ uma perda de massa de $6 \%$, referente à perda de hidroxila. Observou-se uma perda de massa total de $17 \%$. Comparando-se as curvas de análise térmica diferencial das três amostras, pode-se constatar que a temperatura de desidroxilação das amostras A e B são bem próximas, sendo diferenciada para a amostra $C$, que apresenta uma temperatura bem maior que as demais. Essa temperatura depende dos íons que fazem parte da camada octaédrica da estrutura do argilomineral, em função das substituições do Al [9]. Com o aumento das substituições isomórficas, haverá redução da temperatura de desidroxilação, e este comportamento é fortemente influenciado por $\mathrm{Fe}^{3+}$; as montmorilonitas com mais $\mathrm{Fe}^{3+}$ têm temperatura de desidroxilação menor. Fazendo uma correlação com a análise mineralógica (Fig. 2), pode-se constatar que a amostra $\mathrm{C}$ apresentou picos apenas do argilomineral esmectita, já as amostras A e B apresentaram, além de esmectita, picos característicos da caulinita. Portanto, a menor temperatura de desidroxilação detectada para estas amostras pode estar relacionada com a presença da caulinita, que apresenta a transformação para metacaulinita na faixa de 500 a $600{ }^{\circ} \mathrm{C}$, proveniente da desidroxilação.

A Fig. 4 apresenta os difratogramas da evolução mineralógica da amostra A, após tratamento térmico de 800 a $1250{ }^{\circ} \mathrm{C}$, com taxa de aquecimento $30{ }^{\circ} \mathrm{C} / \mathrm{min}$ e patamar de queima $10 \mathrm{~min}$.

Para $800{ }^{\circ} \mathrm{C}$ as fases foram esmectita (JCPDS 10-0357), feldspato (JCPDS 89-8575) e quartzo (JCPDS 46-1045). A $900{ }^{\circ} \mathrm{C}$ não foram observados picos característicos da esmectita, o que concorda com os resultados de outros pesquisadores [11]; no entanto, aparece uma banda na faixa de $2 \theta$ entre 15 a $25^{\circ}$, indicando material amorfo. Para as argilas esmectitas entre 800 e $900{ }^{\circ} \mathrm{C}$ um líquido rico em sílica é formado, proveniente da sílica da camada tetraédrica da estrutura original e dos álcalis [11]. Para $900{ }^{\circ} \mathrm{C}$ surge a
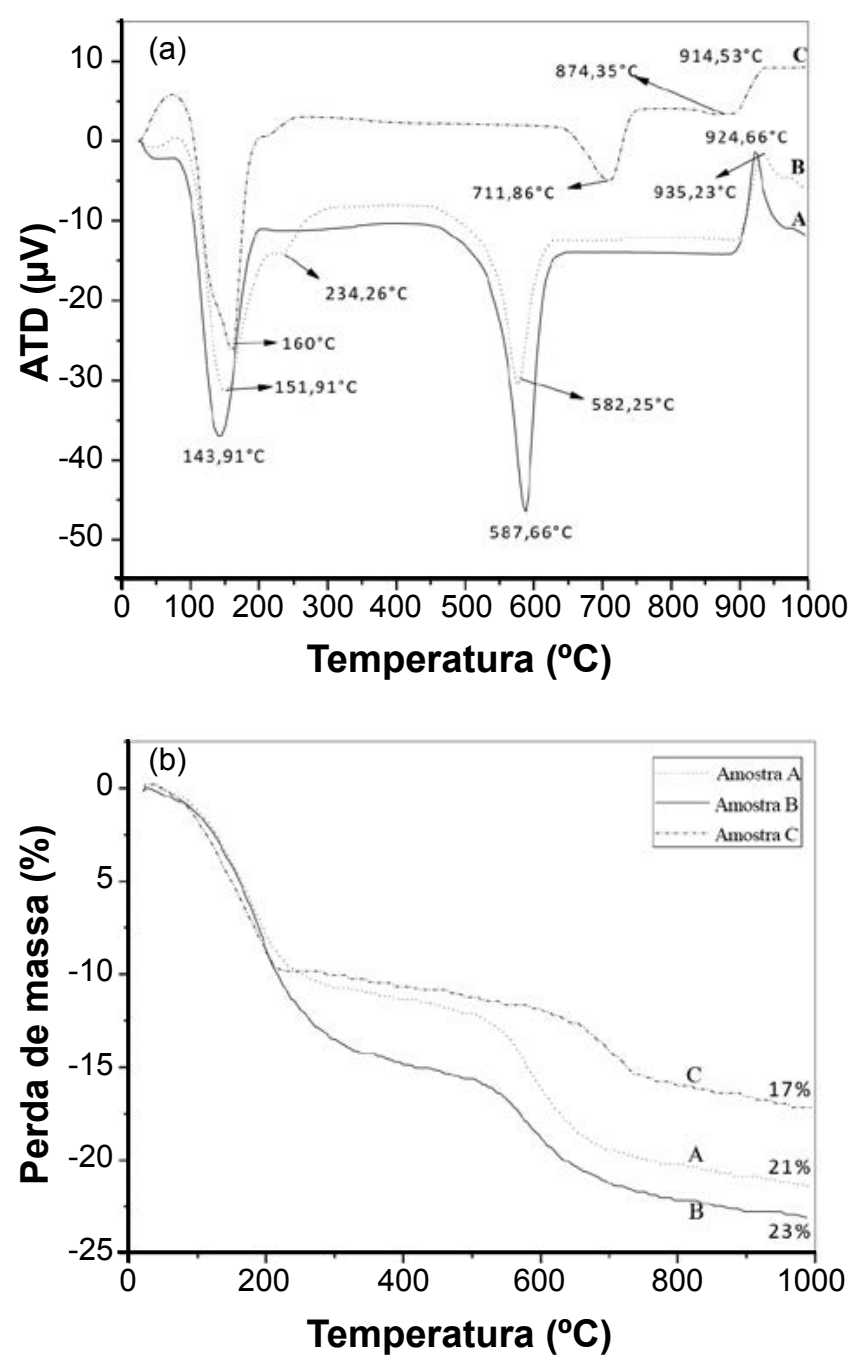

Figura 3: Curvas de análise térmica diferencial (a) e análise termogravimétrica das amostras A, B e C (b).

[Figure 3: Curves of differential thermal analysis (a) and thermogravimetric analysis of $A, B$ and $C$ samples $(b)$.

fase espinélio (JCPDS 21-1152). Nas esmectitas pode haver substituição do Al por Fe e Mg na camada octaédrica. Durante o aquecimento ocorre a desidroxilação, prosseguindo com o tratamento térmico observa-se à destruição da estrutura da argila e surgimento de cristais da fase espinélio [11]. Para $1000{ }^{\circ} \mathrm{C}$, o principal fenômeno observado foi o aumento dos picos de espinélio. Em $1100{ }^{\circ} \mathrm{C}$ começam a surgir os picos de mulita (JCPDF 79-1276) e de cristobalita (JCPDS 89-3435). Nesta faixa de temperatura a mulita derivada de argilominerais apresenta composição mais rica em alumina, com composição próxima de $2 \mathrm{Al}_{2} \mathrm{O}_{3} \cdot \mathrm{SiO}_{2}$, (mulita 2:1), sendo denominada mulita primária $[4,13]$. Com o aumento da temperatura para 1200 e $1250^{\circ} \mathrm{C}$, foram observados picos de mulita e de cristobalita; no entanto, estes apresentaram maior intensidade.

A Tabela II apresenta os percentuais de fases cristalinas da amostra A, a partir de $1100^{\circ} \mathrm{C}$, (temperatura na qual foram detectados os primeiros picos da mulita) pelos difratogramas de raios $\mathrm{X}$ da Fig. 5. Para a temperatura de $1100{ }^{\circ} \mathrm{C}$ as fases 


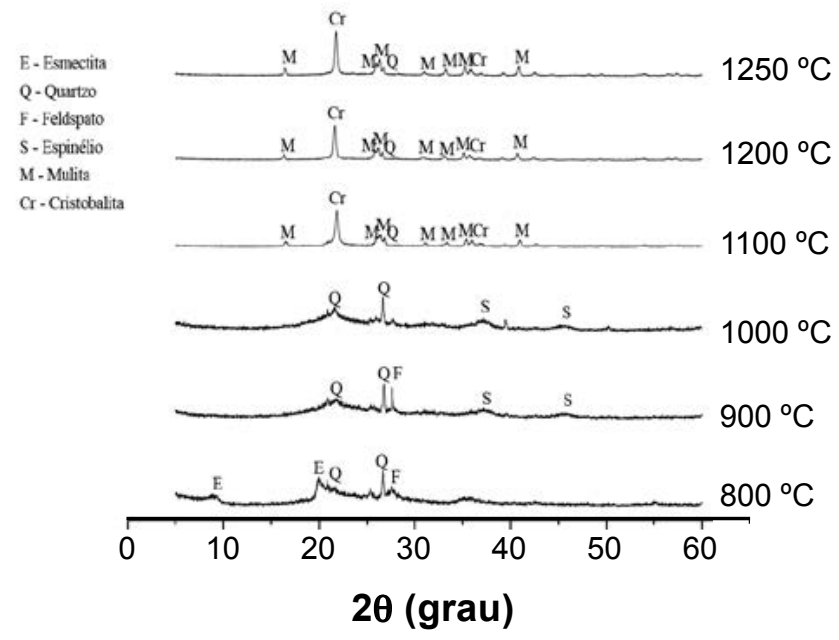

Figura 4: Difratogramas de raios $\mathrm{X}$ da amostra A após tratamento térmico (taxa $30^{\circ} \mathrm{C} / \mathrm{min}$ e patamar $10 \mathrm{~min}$ ).

[Figure 4: XRD patterns of the sample after heat treatment (rate $30{ }^{\circ} \mathrm{C} / \mathrm{min}$ and kept at the maximum temperature for $\left.10 \mathrm{~min}.\right]$

majoritárias foram mulita e cristobalita, com os percentuais de 29,84 e 22,29\%, respectivamente. Outras fases como o espinélio $(4,76 \%)$ e quartzo $(6,97 \%)$ estavam presentes em menor proporção. Com o aumento da temperatura para $1200{ }^{\circ} \mathrm{C}$ observa-se um aumento no percentual destas fases cristalinas, sendo a mulita $(52,29 \%)$ a fase que aparece com maior quantidade na amostra.

Para $1250^{\circ} \mathrm{C}$ observou-se baixo percentual de cristobalita e elevada quantidade de mulita, sendo o valor máximo de $67,59 \%$. Isto pode está relacionado com a importância da fase líquida no processo de cristalização da mulita.

Com relação à cristalinidade pode-se verificar um aumento quando a temperatura passou de 1100 para 1200 ${ }^{\circ} \mathrm{C}$, nesta faixa ocorre à difusão de íons de $\mathrm{Al}$ na fase líquida rica em $\mathrm{Si}$, favorecendo a formação e aumento dos cristais de mulita. Para $1250{ }^{\circ} \mathrm{C}$ a cristalinidade foi reduzida, fato este relacionado ao surgimento de fase vítrea.

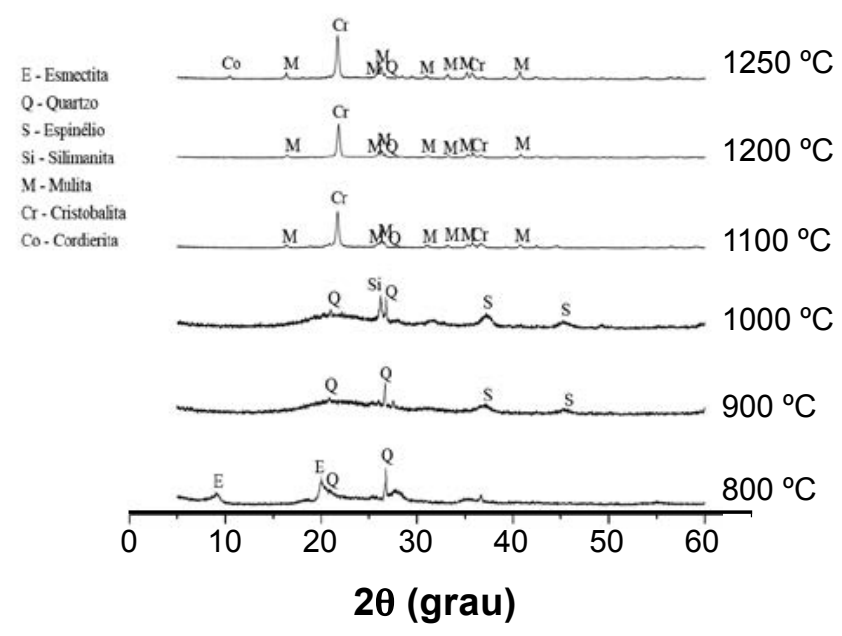

Figura 5: Difratogramas de raios $\mathrm{X}$ da amostra B após tratamento térmico (taxa $30^{\circ} \mathrm{C} / \mathrm{min}$ e patamar $10 \mathrm{~min}$ ).

[Figure 5: XRD patterns of sample B after thermal treatment (rate $30{ }^{\circ} \mathrm{C} / \mathrm{min}$ and kept at the maximum temperature for $10 \mathrm{~min}$ ).]

A Fig. 5 apresenta os difratogramas de raios $\mathrm{X}$ da evolução mineralógica da amostra $\mathrm{B}$, após tratamento térmico de 800 a $1250{ }^{\circ} \mathrm{C}$, com taxa de aquecimento de 30 ${ }^{\circ} \mathrm{C} / \mathrm{min}$ e patamar de queima de $10 \mathrm{~min}$. A $800{ }^{\circ} \mathrm{C}$ as fases são: esmectita (JCPDS: 10-0357) e quartzo (JCPDS: 461045). A presença dos picos de esmectita é um indicativo de que esta é dioctaédrica, pois segundo alguns autores [14] a estrutura da esmectita trioctaédrica é destruída quando ocorre a perda de hidroxilas. Com o aumento da temperatura para $900{ }^{\circ} \mathrm{C}$ não se observa picos característicos da fase esmectitica, caracterizando que para essa temperatura houve a destruição da estrutura da mesma. Para $900{ }^{\circ} \mathrm{C}$ também é possível observar espinélio (JCPDS: 21-1152), assim como, uma banda em $2 \theta$ variando de 15 a 25 , caracterizando a fase amorfa rica em sílica. Depois que a estrutura da argila é destruída, a fase líquida rica em sílica separa-se da camada octaédrica rica em alumina, a qual, então, se rearranja

Tabela II - Percentuais de fases cristalinas após tratamento térmico.

[Table II - Percentage of crystalline phases after heat treatment.]

\begin{tabular}{cccccc}
\hline \multirow{2}{*}{ Amostras } & Quartzo & Espinélio & Cristobalita & Mulita & Cristalinidade \\
\hline A $\left(1100^{\circ} \mathrm{C}\right)$ & 6,97 & 4,76 & 22,29 & 29,84 & 63,86 \\
$\mathrm{~A}\left(1200^{\circ} \mathrm{C}\right)$ & 6,92 & 3,06 & 19,32 & 52,29 & 81,59 \\
$\mathrm{~A}\left(1250^{\circ} \mathrm{C}\right)$ & 6,86 & 4,16 & 1,14 & 67,59 & 79,75 \\
\hline
\end{tabular}

Tabela III - Percentuais de fases após tratamento térmico. [Table III - Percentage of phases after heat treatment.]

\begin{tabular}{ccccccc}
\hline Amostras & Quartzo & Espinélio & Cristobalita & Cordierita & Mulita & Cristalinidade \\
\hline $\mathrm{B}\left(1100^{\circ} \mathrm{C}\right)$ & 5,58 & 9,43 & 22,73 & 0,0 & 35,65 & 73,39 \\
$\mathrm{~B}\left(1200^{\circ} \mathrm{C}\right)$ & 6,85 & 11,12 & 23,50 & 0,0 & 58,53 & 83,93 \\
$\mathrm{~B}\left(1250^{\circ} \mathrm{C}\right)$ & 3,55 & 2,86 & 21,96 & 5,65 & 45,20 & 79,22 \\
\hline
\end{tabular}




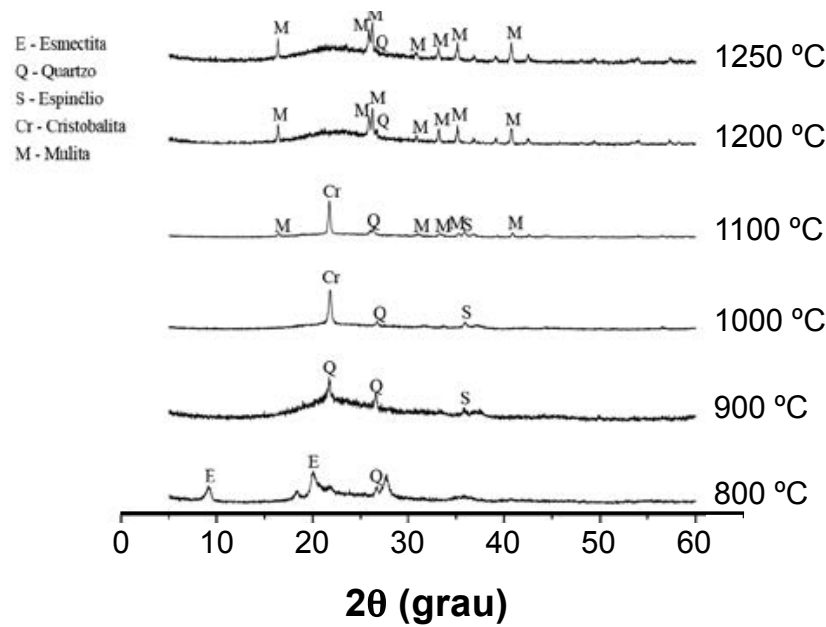

Figura 6: Difratogramas de raios $\mathrm{X}$ da amostra $\mathrm{C}$ após tratamento térmico (taxa $30^{\circ} \mathrm{C} / \mathrm{min}$ e patamar $10 \mathrm{~min}$ ).

[Figure 6: XRD patterns of sample C after heat treatment (rate 30 ${ }^{\circ} \mathrm{C} / \mathrm{min}$ and kept at the maximum temperature for $10 \mathrm{~min}$ ).]

formando a fase espinélio [11]. Para $1000{ }^{\circ} \mathrm{C}$ surge uma nova fase, a silimanita (JCPDS: 38-0471), provavelmente relacionada à grande quantidade de sílica que reagiu durante o tratamento térmico. Em $1100{ }^{\circ} \mathrm{C}$ começam a surgir os primeiros picos de mulita (JCPDS: 79-1276) e picos de $\beta$-cristobalita (JCPDS: $89-3435$ ). A $1200{ }^{\circ} \mathrm{C}$ os picos de mulita aumentam. A $1250{ }^{\circ} \mathrm{C}$ ocorre a fase cordierita (JCPDS: 89-1487), além de mulita e cristobalita.

A Tabela III apresenta os percentuais de fases cristalinas da amostra $\mathrm{B}$, a partir de $1100^{\circ} \mathrm{C}$, (temperatura na qual foram detectados os primeiros picos da mulita) pelos difratogramas de raios X da Fig. 6.

Fazendo uma análise da Tabela III, para 1100 e 1200 ${ }^{\circ} \mathrm{C}$ a mulita e a cristobalita foram as fases majoritárias; no entanto para $1250{ }^{\circ} \mathrm{C}$, de acordo com o resultado já observado no difratograma, surge a fase cordierita, apresentado um percentual de $5,65 \%$. Para $1250{ }^{\circ} \mathrm{C}$ observase um comportamento com relação ao grau de cristalinidade semelhante ao da amostra A.

AFig. 6 apresenta os difratogramas de raios X da evolução mineralógica da amostra $C$, após tratamento térmico de 800 a $1250{ }^{\circ} \mathrm{C}$ com taxa de aquecimento $30{ }^{\circ} \mathrm{C} / \mathrm{min}$ e patamar de queima $10 \mathrm{~min}$. A $800^{\circ} \mathrm{C}$ as fases são esmectita (JCPDS 10-0357) e quartzo (JCPDS 46-1045). Aumentando a temperatura para $900{ }^{\circ} \mathrm{C}$ pode-se observar uma banda em $2 \theta$ variando de 15 a $30^{\circ}$, relacionada com a fase amorfa, que foi formada a partir da sílica proveniente da destruição da
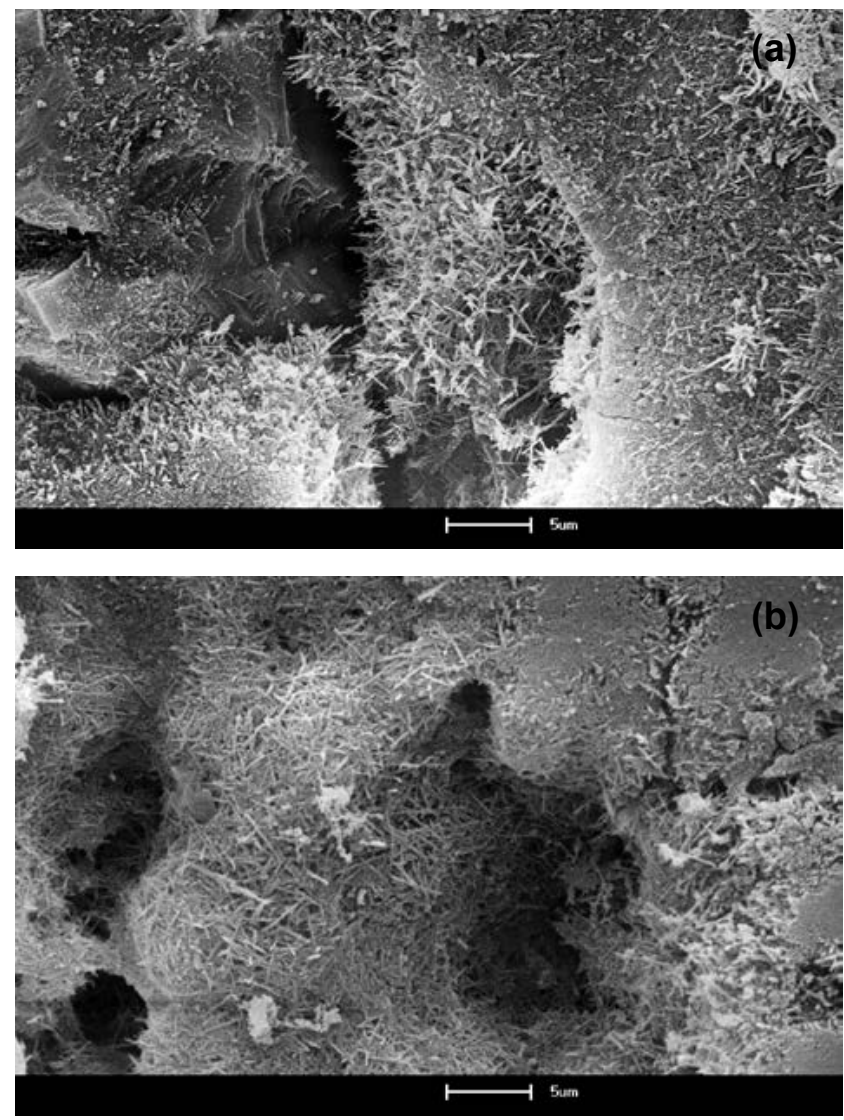

Figura 7: Micrografias obtidas por microscopia eletrônica de varredura das amostras A e B, da esquerda para a direita.

[Figure 7: SEM micrographs of samples $A$ and $B$, left to right.]

estrutura da esmectita e dos álcalis presentes. O surgimento de picos característicos da fase tipo espinélio (JCPDS 211152) foi observado a partir de $900{ }^{\circ} \mathrm{C}$. Para $1000^{\circ} \mathrm{C}$ surgem os picos de cristobalita (JCPDS 89-3435) e a $1100{ }^{\circ} \mathrm{C}$ os de mulita (JCPDS 79-1276), que se intensificam com o aumento da temperatura para 1200 e $1250{ }^{\circ} \mathrm{C}$. De $1200{ }^{\circ} \mathrm{C}$ e $1250{ }^{\circ} \mathrm{C}$ surge novamente uma banda entre 15 e $25^{\circ}$, podendo estar relacionada à fusão da fase espinélio.

A Tabela IV apresenta os percentuais de fases da amostra C obtidos a partir dos difratogramas de raios X da Fig. 6 após tratamento térmico. A amostra $\mathrm{C}$ para $1100{ }^{\circ} \mathrm{C}$ teve como fases majoritárias a cristobalita e a mulita. Com o aumento da temperatura para 1200 e $1250^{\circ} \mathrm{C}$, a cristalinidade diminui consideravelmente, o que está relacionado com o surgimento da fase amorfa, caracterizada pela banda observada nos difratogramas da Fig. 6. Comparando a quantidade de mulita

Tabela IV - Percentuais de fases após tratamento térmico.

[Table IV - Percentage of phases after heat treatment.]

\begin{tabular}{cccccc}
\hline \multirow{2}{*}{ Amostras } & Quartzo & Espinélio & $\begin{array}{c}\% \\
\text { Cristobalita }\end{array}$ & Mulita & Cristalinidade \\
\hline $\mathrm{C}\left(1100^{\circ} \mathrm{C}\right)$ & 2,52 & 7,87 & 8,05 & 40,30 & 58,74 \\
$\mathrm{C}\left(1200^{\circ} \mathrm{C}\right)$ & 2,08 & 0,0 & 0,66 & 39,89 & 42,63 \\
$\mathrm{C}\left(1250^{\circ} \mathrm{C}\right)$ & 1,61 & 0,0 & 0,68 & 36,88 & 39,17 \\
\hline
\end{tabular}


da amostra C com as outras amostras, A e B, observou-se um menor percentual de mulita, o que já era esperado, em função da menor relação $\mathrm{Al} / \mathrm{Si}$.

A Fig. 7 apresenta as micrografias das amostras A e B após tratamento térmico a $1250{ }^{\circ} \mathrm{C}, 30{ }^{\circ} \mathrm{C} / \mathrm{min}$ e patamar de $10 \mathrm{~min}$. Podem-se observar cristais de mulita com característica acicular, com formato de agulhas, com dimensões de aproximadamente $15 \mu \mathrm{m}$. Além disso, é perceptível a presença de partículas de tamanhos maiores que, provavelmente, são de quartzo e cristobalita. De acordo com os resultados de EDS, além de $\mathrm{Si}$ e Al, Fe também estava presente nas agulhas de mulita. Estas observações concordam com os resultados da Ref. [5], na qual foi observado que o $\mathrm{Fe}$ tende a formar solução sólida com a mulita, cuja solubilidade pode ser de até $12 \%$ em peso.

\section{CONCLUSÕES}

A partir dos estudos sobre diferentes tratamentos térmicos em argilas esmectitícas, pode-se concluir que a composição das argilas esmectíticas, a temperatura e a relação $\mathrm{Al} / \mathrm{Si}$ influenciaram na quantidade de mulita formada. A amostra com maior quantidade de magnésio levou à formação da fase cordierita. Os cristais de mulita apresentaram forma de agulhas, com dimensão de aproximadamente $15 \mu \mathrm{m}$ a $1250^{\circ} \mathrm{C}$. A análise da composição das agulhas de mulita revelou a presença de $\mathrm{Fe}$, evidenciando que este tende a ser incorporado na mulita na forma de solução sólida.

\section{AGRADECIMENTOS}

Ao CNPq (306554/2010-0) e à CAPES (2494/2011) pelo apoio financeiro.

\section{REFERÊNCIAS}

[1] A. Michot, D. S. Smith, S. Degot, C. Gault, J. Eur. Ceram. Soc. 28 (2008) 2639-2644.

[2] J. Li, H. Lin, J. Wu. J. Eur. Ceram. Soc. 29 (2009) 29292936.

[3] E. Kamseu, E. C. Leonelli, D. N. Boccaccini, P. Veronesi, P. Miselli, G. Pellacani, U. Chinje Melo, Ceram. Int. 33 (2007) 851-857.

[4] W. E. Lee, Y. Iqbal, J. Eur. Ceram. Soc. 21 (2001) 2583 2586.

[5] S. M. Johnson, J. A. Pask, Am. Ceram. Soc. Bull. 61 (1982) 838-842.

[6] I. Ganesh, J. M. F. Ferreira, Ceram. Int. 35 (2009) 2007 2015.

[7] G. Lecomte-Nana, J. P. Bonnet, N. Soro, J. Eur. Ceram. Soc. 33, 4 (2013) 669-677.

[8] W. E. Lee, G. P. Souza, C. J. McConville, T. Tarvornpanich, Y. Iqbal, J. Eur. Ceram. Soc. 28 (2008) 46571.

[9] P. Wu, H. Wu, R. Li, Spectrochim. Acta - Part A 61 (2005) 3020-3025.

[10] J. Gomes, J. M. Cartaxo, R. R. Menezes, G. A. Neves, M. I. Brasileiro, L. N. L. Santana, Mater. Sci. Fórum 727728 (2012) 781-786.

[11] C. J. Mcconville, W. E. Lee, J. Am. Ceram. Soc. 88 (2005) 2267-2276.

[12] P. Souza Santos, Ciência e Tecnologia de Argilas, $2^{\mathrm{a}}$ Ed., Ed. Edgard Blucher Ltda., S. Paulo, SP (1992).

[13] M. V. M. Magliano, V. C. Pandolfelli, Cerâmica 56, 340 (2010) 368-375.

[14] H. Bayram, M. Onal, H. Yilmaz, Y. Sarikaya, J. Therm. Anal. Calorim. 101 (2010) 873-879.

(Rec. 15/11/2013, Ac. 25/01/2014) 